\title{
Radiotherapy of Primary or Recurrent Bladder Cancer in the Very Elderly
}

\author{
STEFAN JANSSEN ${ }^{1}$, LISA MANIG ${ }^{1}$, STEVEN E. SCHILD ${ }^{2}$ and DIRK RADES ${ }^{1}$ \\ ${ }^{1}$ Department of Radiation Oncology, University of Lübeck, Lübeck, Germany; \\ ${ }^{2}$ Department of Radiation Oncology, Mayo Clinic, Scottsdale, AZ, U.S.A.
}

\begin{abstract}
Aim: The number of very elderly patients with cancer is growing and requires particular attention. The role of organ-sparing irradiation in patients with bladder cancer aged $\geq 80$ years was investigated. Patients and Methods: In 29 very elderly ( $\geq 80$ years) patients irradiated for bladder cancer, 12 characteristics were analysed for survival: indication, gender, age, Karnofsky performance score (KPS), $T$-/N-category, tumour grade, pack years, smoking during irradiation, radiation dose, interruption of irradiation $>5$ days and concurrent chemotherapy. Results: On univariate analysis, primary treatment $(p=0.001), K P S>70(p=0.026)$ and not smoking during radiotherapy $(p<0.001)$ were associated with better survival. A strong trend for such association was observed for female gender $(p=0.054),<40$ pack years $(p=0.064)$ and concurrent chemotherapy $(p=0.061)$, and a trend for no interruption of irradiation $(p=0.09)$. On multivariate analysis, primary treatment $(p=0.006)$ and not smoking during radiotherapy $(p=0.038)$ maintained significance. Conclusion: Very elderly patients irradiated for bladder cancer may benefit from concurrent chemotherapy. Smoking during irradiation and interruptions of irradiation should be avoided.
\end{abstract}

Due to demographic changes, the numbers of elderly and very elderly cancer patients are constantly increasing (1-6). This trend also applies to patients with cancer of the urinary bladder (4). For patients with non-metastatic bladder cancer, many oncology centres consider a radical cystectomy the standard of care. However, radical cystectomy has been reported to be associated with significant complications in up to $30 \%$ of patients and has a perioperative mortality rate of up

Correspondence to: Professor Dirk Rades, Department of Radiation Oncology, University of Lübeck, Ratzeburger Allee 160, D-23552 Lübeck, Germany. Tel: +49 45150045401, e-mail: rades.dirk@gmx.net

Key Words: Very elderly patients, bladder cancer, organ preservation, radiotherapy, radio-chemotherapy. to $3 \%$ (7-9). Very elderly patients often present with significant co-morbidities that preclude aggressive treatment such as radical cystectomy. Alternatively, these patients can be treated with less aggressive organ-preserving approaches, mostly including a transurethral resection of the bladder (TURB) and subsequent local irradiation (10). Irradiation can be intensified by administration of concurrent radio-sensitizing chemotherapy. However, the addition of chemotherapy may not be possible in many very elderly patients due to their comorbidities affecting organs such as the heart, liver or kidneys. These patients often undergo TURB plus radiotherapy alone.

Since bladder cancer is relatively uncommon, few data are available regarding the treatment of very elderly patients presenting with this particular malignancy. The present study aimed to provide additional data regarding very elderly patients with urinary bladder cancer who received local irradiation or radio-chemotherapy for a primary or recurrent tumour. Several characteristics and their potential impact on the patients' survival prognosis were investigated.

\section{Patients and Methods}

A cohort of 29 very elderly patients aged 80 years or older was investigated in this retrospective study. The patients were irradiated for primary $(\mathrm{N}=17)$ or recurrent $(\mathrm{N}=12)$ non-metastatic bladder cancer. All but one patient had undergone upfront TURB. Concurrent chemotherapy with either cisplatin $(\mathrm{N}=5)$, paclitaxel $(\mathrm{N}=6)$, cisplatin/paclitaxel $(\mathrm{N}=1)$ or gemcitabine $(\mathrm{N}=1)$ was administered to 13 patients. In 15 patients, the three-dimensional conformal irradiation was delivered to a total dose of 59.4 Gy given in 28 fractions of $1.8 \mathrm{~Gy}$. In the other 14 patients, total doses ranged from $27 \mathrm{~Gy}$ to $55.8 \mathrm{~Gy}$, with doses per faction ranging from 1.8 to 3.0 Gy. The patient characteristics are shown in Table I.

For these 29 patients, 12 characteristics were investigated for potential impact on survival following irradiation: indication of irradiation (primary $v s$. recurrent tumour), gender, age at irradiation ( $\leq 83$ vs. $>83$ years; median age $=83$ years; range $=80-91$ years $)$, Karnofsky performance score (KPS; $\leq 70$ vs. >70), T-category (T12a vs. T>2a vs. T3-4), N-category ( 0 0 vs. $\mathrm{N}+$ ), grading (G2 vs. G3), pack years of smoking $(<40 v s . \geq 40)$, smoking during the irradiation period (no $v s$. yes), equivalent radiation dose in 2 -Gy fractions 
Table I. Characteristics that were investigated for a potential impact on survival.

\begin{tabular}{|c|c|c|}
\hline & $\begin{array}{c}\text { Number of } \\
\text { patients }\end{array}$ & $\begin{array}{c}\text { Proportion } \\
(\%)\end{array}$ \\
\hline \multicolumn{3}{|l|}{ Indication for irradiation } \\
\hline Primary treatment & 17 & 59 \\
\hline Treatment of a recurrence & 12 & 41 \\
\hline \multicolumn{3}{|l|}{ Gender } \\
\hline Female & 11 & 38 \\
\hline Male & 18 & 62 \\
\hline \multicolumn{3}{|l|}{ Age at irradiation } \\
\hline$\leq 83$ Years & 15 & 52 \\
\hline$>83$ Years & 14 & 48 \\
\hline \multicolumn{3}{|l|}{ Karnofsky performance score } \\
\hline$\leq 70$ & 11 & 38 \\
\hline$>70$ & 18 & 62 \\
\hline \multicolumn{3}{|l|}{ T-Stage } \\
\hline $1-2 \mathrm{a}$ & 6 & 21 \\
\hline$>2 \mathrm{a}$ & 9 & 31 \\
\hline $3-4$ & 14 & 48 \\
\hline \multicolumn{3}{|l|}{$\mathrm{N}$-Stage } \\
\hline 0 & 23 & 79 \\
\hline $1-3$ & 6 & 21 \\
\hline \multicolumn{3}{|l|}{ Grading } \\
\hline $\mathrm{G} 2$ & 4 & 14 \\
\hline G3 & 25 & 86 \\
\hline \multicolumn{3}{|l|}{ Pack years } \\
\hline$<40$ & 25 & 86 \\
\hline$\geq 40$ & 4 & 14 \\
\hline \multicolumn{3}{|l|}{ Smoking during irradiation } \\
\hline No & 26 & 90 \\
\hline Yes & 3 & 10 \\
\hline \multicolumn{3}{|l|}{ EQD2 } \\
\hline$\leq 54.9 \mathrm{~Gy}$ & 14 & 48 \\
\hline$<58.4 \mathrm{~Gy}$ & 15 & 52 \\
\hline \multicolumn{3}{|l|}{ Interruption of irradiation } \\
\hline No & 25 & 86 \\
\hline Yes & 4 & 14 \\
\hline \multicolumn{3}{|l|}{ Concurrent chemotherapy } \\
\hline No & 16 & 55 \\
\hline Yes & 13 & 45 \\
\hline
\end{tabular}

EQD2: Equivalent dose in 2 Gy fractions.

(EQD2; $\leq 54.9$ Gy vs. 58.4 Gy), interruption of irradiation by $>5$ days (no $v s$. yes) and delivery of concurrent chemotherapy (no vs. yes).

Survival rates were estimated with the Kaplan-Meier method supplemented with the log-rank test (11). The characteristics that were found to be significant on univariate analyses $(p<0.05)$ or found to have a strong trend $(p<0.07)$ for association with survival, were additionally included in a multivariate analysis using the Cox proportional hazards model.

\section{Results}

On univariate analysis, primary treatment $(p=0.001)$, a KPS $>70 \quad(p=0.026)$ and not smoking during radiotherapy $(p<0.001)$ were significantly associated with better survival
Table II. Univariate analysis including survival rates at 1 and 3 years.

\begin{tabular}{|c|c|c|c|}
\hline & At 1 year & At 3 years & $p$-Value \\
\hline \multicolumn{4}{|l|}{ Indication for irradiation } \\
\hline Primary treatment & 82 & 74 & \\
\hline Treatment of a recurrence & 33 & 8 & 0.001 \\
\hline \multicolumn{4}{|l|}{ Gender } \\
\hline Female & 81 & 69 & \\
\hline Male & 50 & 29 & 0.054 \\
\hline \multicolumn{4}{|l|}{ Age at irradiation } \\
\hline$\leq 83$ Years & 59 & 39 & \\
\hline$>83$ Years & 64 & 48 & 0.52 \\
\hline \multicolumn{4}{|l|}{ Karnofsky performance score } \\
\hline$\leq 70$ & 42 & n.a. & \\
\hline$>70$ & 72 & 58 & 0.026 \\
\hline \multicolumn{4}{|l|}{ T-Stage } \\
\hline $1-2 \mathrm{a}$ & 67 & 44 & \\
\hline$>2 \mathrm{a}$ & 56 & 56 & \\
\hline $3-4$ & 62 & 36 & 0.72 \\
\hline \multicolumn{4}{|l|}{$\mathrm{N}$-Stage } \\
\hline 0 & 61 & 41 & \\
\hline $1-3$ & 67 & 67 & 0.36 \\
\hline \multicolumn{4}{|l|}{ Grading } \\
\hline G2 & 75 & 75 & \\
\hline G3 & 59 & 39 & 0.38 \\
\hline \multicolumn{4}{|l|}{ Pack years } \\
\hline$<40$ & 68 & 49 & \\
\hline$\geq 40$ & 0 & 0 & 0.064 \\
\hline \multicolumn{4}{|l|}{ Smoking during irradiation } \\
\hline No & 69 & 49 & \\
\hline Yes & 0 & 0 & $<0.001$ \\
\hline \multicolumn{4}{|l|}{ EQD2 } \\
\hline$\leq 54.9 \mathrm{~Gy}$ & 55 & 39 & \\
\hline$<58.4 \mathrm{~Gy}$ & 67 & 48 & 0.69 \\
\hline \multicolumn{4}{|l|}{ Prolongation of irradiation } \\
\hline No & 63 & 53 & \\
\hline Yes & 50 & 0 & 0.09 \\
\hline \multicolumn{4}{|l|}{ Concurrent chemotherapy } \\
\hline No & 50 & 29 & \\
\hline Yes & 76 & 65 & 0.061 \\
\hline
\end{tabular}

EQD2: Equivalent dose in 2 Gy fractions, n.a.: not available. Significant $p$-values are shown in bold.

rates. A strong trend for an improved survival was observed for female gender $(p=0.054),<40$ pack years $(p=0.064)$ and the administration of concurrent chemotherapy $(p=0.061)$. In addition, a trend was found for avoiding breaks of $>5$ days $(p=0.09)$. The complete results of the univariate analyses are shown in Table II.

On multivariate analysis, primary treatment [hazard ratio $(\mathrm{HR})=4.85 ; 95 \%$-confidence interval $(\mathrm{CI})=1.57-18.12$; $p=0.006]$ and not smoking during radiotherapy $(\mathrm{HR}=6.09$; 95\%-CI=1.12-29.22; $p=0.038)$ maintained significance. A KPS $>70(\mathrm{HR}=2.13 ; 95 \%$-CI $=0.68-96.54 ; p=0.19)$, female gender $(\mathrm{HR}=1.58 ; 95 \%-\mathrm{CI}=0.33-8.94 ; p=0.57),<40$ pack years $(\mathrm{HR}=2.08 ; 95 \%$-CI: $0.21-52.63 ; p=0.57)$ and the 
administration of concurrent chemotherapy (HR=1.95; 95\%$\mathrm{CI}=0.55-7.87 ; p=0.31)$ did not achieve significance in the multivariate analysis.

\section{Discussion}

Very elderly patients with non-metastatic urinary bladder cancer requiring local treatment are often unable to tolerate radical cystectomy and are treated with less aggressive approaches including irradiation (7-10). Since these patients are uncommon, only very few studies are available that focused particularly on this subgroup. The current study was conducted to provide additional information regarding their radiotherapy outcomes to help optimize future patient care.

Treatment for a primary tumour resulted in significantly better outcomes than that of a recurrence on both univariate and multivariate analyses. This is not surprising because at the time of a recurrence, patients often have a worse performance status and have already received anticancer treatment, moreover, recurrent tumours are frequently more difficult to control than primary lesions (12). Smoking during the period of irradiation was also significantly associated with a worse survival on both univariate and multivariate analyses. A negative association between smoking and treatment outcomes has been reported for patients irradiated for non-small-cell lung cancer (13). In the multivariate analysis of a retrospective study of 181 patients, smoking during treatment resulted in worse locoregional control ( $p=0.029)$. In the present study, a strong trend was observed for an association between $<40$ pack years of smoking and favourable survival on univariate analysis. A similar correlation has been reported for patients with cancer of the oropharynx (14). In the present study, female gender showed a strong trend for being associated with improved survival in the univariate analysis. A positive association between female gender and survival was also demonstrated in patients with metastatic disease (15). Another important finding of the present study is that very elderly patients appear to benefit from the addition of concurrent chemotherapy to irradiation, which has already been shown in studies of bladder cancer in patients of any age with primary or recurrent tumours $(10,12)$. In addition, a certain trend was identified that interruptions of irradiation reduce survival. This has also been found in patients of any age treated for locally advanced head and neck cancer (16). The comparisons with the literature show that the factors having an impact on the results of irradiation of localized bladder cancer in very elderly patients are consistent with the outcomes of many other treatment situations.

Weaknesses of this study include the cohort size and the retrospective nature of this analysis. However, there are so few available data on very elderly patients with bladder cancer; the Authors feel that these data are important in order to help optimize therapy in elderly patients, who present more commonly these days as people live longer than they did in the past.

In conclusion, very elderly patients irradiated for bladder cancer appear to benefit from the addition of concurrent chemotherapy. In order to achieve best possible outcome, smoking and interruptions during treatment should be avoided if possible. Very elderly patients irradiated for bladder cancer require maximum support from their medical staff to accomplish these goals.

\section{Conflicts of Interest}

On behalf of all Authors, the corresponding Author states that there is no conflict of interest related to this study.

\section{References}

1 Smetana K Jr., Lacina L, Szabo P, Dvořánková B, Brož P and Šedo A: Ageing as an important risk factor for cancer. Anticancer Res 36: 5009-5017, 2016.

2 Inomata M, Shimokawa K, Tokui K, Taka C, Okazawa S, Kambara K, Yamada T, Miwa T, Hayashi R, Kashii T, Matsui S and Tobe K: Appetite loss as an adverse effect during treatment with EGFR-TKIs in elderly patients with non-small cell lung cancer. Anticancer Res 36: 4951-4954, 2016.

3 Shah BK, Bista A and Sharma S: Survival trends in elderly patients with glioblastoma in the United States: a populationbased study. Anticancer Res 36: 4883-4886, 2016.

4 Maebayashi T, Ishibashi N, Aizawa T, Sakaguchi M, Sato K, Matsui T, Yamaguchi K and Takahashi S: Radiotherapy for muscle-invasive bladder cancer in very elderly patients. Anticancer Res 36: 4763-4769, 2016.

5 Itoh S, Kohnoe S, Shirabe K, Yoshida D, Kawanaka H, Yoshizumi T, Ikegami T, Yamashita Y, Kurihara T and Maehara Y: Validity of hepatic or pancreatic resection for elderly patients aged 85 years or older at a single community hospital in Japan. Anticancer Res 36: 4289-4292, 2016.

6 Käsmann L, Janssen S and Rades D: Karnofsky performance score, radiation dose and nodal status predict survival of elderly patients irradiated for limited-disease small-cell lung cancer. Anticancer Res 36: 4177-4180, 2016.

7 Konety BR, Allareddy V and Herr H: Complications after radical cystectomy: analysis of population-based data. Urology 68: 5864, 2006.

8 Manoharan M, Ayyathurai R and Soloway MS: Radical cystectomy for urothelial carcinoma of the bladder: an analysis of perioperative and survival outcome. BJU Int 104: 1227-1232, 2009.

9 Koga $\mathrm{F}$ and Kihara K: Selective bladder preservation with curative intent for muscle-invasive bladder cancer: a contemporary review. Int J Urol 19: 388-401, 2012.

10 Rodel C, Grabenbauer GG, Kühn R, Papadopoulos T, Dunst J, Meyer M, Schrott KM and Sauer R: Combined-modality treatment and selective organ preservation in invasive bladder cancer: long-term results. J Clin Oncol 20: 3061-3071, 2002.

11 Kaplan E and Meier P: Nonparametric estimation from incomplete observation. J Am Stat Assoc 53: 457-481, 1958. 
12 Rades D, Manig L, Janssen S and Schild SE: Concurrent chemotherapy improves the overall survival of patients irradiated for locally recurrent bladder cancer. Anticancer Res 37: 14851488, 2017.

13 Rades D, Setter C, Schild SE and Dunst J: Effect of smoking during radiotherapy, respiratory insufficiency, and hemoglobin levels on outcome in patients irradiated for non-small-cell lung cancer. Int J Radiat Oncol Biol Phys 71: 1134-1142, 2008.

14 Gillison ML, Zhang Q, Jordan R, Xiao W, Westra WH, Trotti A, Spencer S, Harris J, Chung CH and Ang KK: Tobacco smoking and increased risk of death and progression for patients with p16-positive and p16-negative oropharyngeal cancer. J Clin Oncol 30: 2102-2111, 2012.
15 Rades D, Dziggel L, Segedin B, Oblak I, Nagy V, Marita A, Schild SE, Trang NT and Khoa MT: A new survival score for patients with brain metastases from non-small cell lung cancer. Strahlenther Onkol 189: 777-781, 2013.

16 Rades D, Stoehr M, Kazic N, Hakim SG, Walz A, Schild SE and Dunst: Locally advanced stage IV squamous cell carcinoma of the head and neck: Impact of pre-radiotherapy hemoglobin level and interruptions during radiotherapy. Int J Radiat Oncol Biol Phys 70: 1108-1114, 2008.

Received April 8, 2017

Revised April 21, 2017

Accepted April 25, 2017 